Gut, 1980, 21, 376-380

\title{
Agglutinins to bacteria in Crohn's disease
}

\author{
N MATTHEWS, J F MAYBERRY, J RHODES, L NEALE, J MUNRO, \\ F WENSINCK, G H K LAWSON, A C ROWLAND, G A BERKHOFF, AND \\ S W BARTHOLD
}

From the Departments of Gastroenterology, Medical Microbiology, and Public Health Laboratory Service, University Hospital of Wales, Heath Park, Cardjff; Department of Medical Microbiology, Erasmus University, Rotterdam; Department of Veterinary Pathology, University of Edinburgh, Veterinary Field Station, Easter Bush, Rosslyn; Department of Preventive Medicine, University of Florida, Gainesville, Florida, USA; and the Section of Comparative Medicine, Yale University School of Medicine, New Haven, Connecticut, USA

SUMmaRY Sera from patients with Crohn's disease were tested for antibodies against organisms which are thought to cause inflammatory bowel disease in animals, or have been implicated in human Crohn's disease. Control sera were collected from healthy individuals and patients with ulcerative colitis. Sera from Crohn's disease and controls failed to agglutinate Clostridium colinum or Campylobacter sputorum subsp. mucosalis and two strains of Mycobacterium paratuberculosis (M26 and M27). Most of the sera agglutinated a Citrobacter freundii variant, Mycobacterium paratuberculosis (M28) and Mycobacterium avium (M41) but Crohn's disease sera did not differ from controls. A complement fixation test against Chlamydia gave more positive reactions in patients with Crohn's disease and colitis than in healthy controls. There was a clear difference between the sera from patients with Crohn's disease and other sera, including ulcerative colitis, in agglutination tests with the commensal coccoid rods of the genera Eubacterium and Peptostreptococcus; in these tests $54 \%$ of sera from Crohn's disease were positive compared with $11 \%$ in ulcerative colitis and none of the sera from healthy controls. All the results were essentially negative with the exception of those from Eubacterium and Peptostreptococcus and these bacteria merit investigation.

There has been a marked rise in the incidence of Crohn's disease in the last 20 years which cannot simply be attributed to greater recognition of the condition. ${ }^{1}$ In such circumstances an infectious agent may play an important role, although attempts to identify an organism have been unsuccessful. We have used an unusual approach and have examined sera for the presence of antibodies against a variety of organisms known to cause inflammatory bowel disease in animals, ${ }^{2}$ as well as organisms which have recently been examined in patients with Crohn's disease. Patients with ulcerative colitis and healthy volunteers were used as controls to compare with patients who had Crohn's disease.

In animals a variety of microorganisms are associated with lesions in the terminal ileum and colon which resemble some of the features of Crohn's disease. Although these differ in some respects from Crohn's disease, it is possible that one

Received for publication 15 January 1980 of the pathogens or a related organism may be involved in Crohn's disease. Among the more likely organisms are Mycobacterium paratuberculosis, which causes Johne's disease in ruminants, ${ }^{3}$ Clostridium colinum, which is the agent of quail enteritis, ${ }^{4-6}$ Campylobacter sputorum subspecies mucosalis, which is the bacterium associated with porcine intestinal adenomatosis, ${ }^{7}$ and a variant of Citrobacter freundii, which causes mucosal hyperplasia of the colon in mice. ${ }^{8}$ It is pertinent to note that most of these organisms have proved difficult to culture.

There have been many suggestions that microorganisms are implicated in Crohn's disease and one recent candidate is Chlamydia. ${ }^{9-11}$ Wensinck $^{1213}$ has focused attention on another abnormality in patients with Crohn's disease: he found that the faecal flora from patients differed from healthy controls. It contained increased numbers of anaerobic gramnegative rods and gram-positive coccoid rods of the genera Eubacterium and Peptostreptococcus. This difference was not affected by the duration of disease 
or by ileocaecal resection and was considered to be independent of the disease process. In his study it was noted that agglutination of certain strains of Eubacterium and Peptostreptococcus occurred more frequently with sera from patients with Crohn's disease than with sera from healthy individuals.

\section{Methods}

\section{SERA}

Samples of sera were obtained from 100 patients with Crohn's disease and 40 with ulcerative colitis; cases where the differential diagnosis between Crohn's disease and ulcerative colitis had not been fully established were excluded from the study. Sera from 60 healthy controls were obtained from volunteers who worked in the hospital. Some of the sera were not tested against all bacterial preparations.

\section{BACTERIAL PREPARATIONS}

Campylobacter sputorum subsp. mucosalis (strain 253/72), ${ }^{14}$ Clostridium colinum (strain ATCC 27770), ${ }^{5}$ and Citrobacter freundii (strain 4280$)^{8}$ were all isolated from diseased animals by authors in this paper who are working with the organisms; bacterial suspensions were prepared in $0.12 \%(\mathrm{w} / \mathrm{v})$ formaldehyde solution. Three strains of Mycobacterium paratuberculosis (M26, M27, M28) and Myocbacterium avium (type 1 , strain $\mathrm{M} 41)^{15}$ were also isolated from diseased animals and prepared as suspensions in $0.5 \%$ phenol; M26 cross-reacted antigenically with Mycobacterium avium type 2 and M27 and M28 cross-reacted with Mycobacterium avium polyvalent sera composed of types $1,2,3$, and 18 but failed to react with a specific serotype (Personal communication). The coccoid rods included Eubacterium contortum (strains ME44 and ME47) and Eubacterium rectale (ME46) isolated from patients with Crohn's disease in Rotterdam ${ }^{12}$ and Peptostreptococcus productus (strain C18). One to two-day anaerobic cultures of coccoid rods were incubated with $0.2 \%(\mathrm{w} / \mathrm{v})$ formaldehyde solution, incubated for $18 \mathrm{~h}$ at $37^{\circ} \mathrm{C}$, washed twice in isotonic saline, and resuspended in saline containing $0.01 \%$ (w/v) sodium ethylmercurithiosalicylate.

All of the bacteria except the Mycobacteria were resuspended before examination in phosphate buffered isotonic saline at $\mathrm{pH} \mathbf{7 \cdot 2}$ to give a $1 \%$ suspension; when Mycobacteria were tested $0.1 \%$ normal rabbit serum and $1 \%$ Tween 80 were added to prevent spontaneous agglutination.

\section{AGGLUTINATION TESTS}

Various dilutions of the sera $(40 \mu \mathrm{l})$ and the bacterial suspensions $(20 \mu \mathrm{l})$ were mixed together for five minutes using a Dynatech-microshaker in the wells of flat-bottomed microtest trays (Sterilin M29ARTL). Agglutination patterns were examined with an inverted microscope using $\times 125$ magnification, immediately after solutions had been mixed in the case of the coccoid rods, but after a further 60 minutes at $37^{\circ} \mathrm{C}$ with Citrobacter freundii and after 30 minutes at $37^{\circ} \mathrm{C}$ followed by 16 to 20 hours at room temperature for Clostridium colinum, Campylobacter sputorum, and the mycobacteria. Neat sera were used in tests against Clostridium colinum, Campylobacter sputorum and the coccoid rods, at $1: 4$ dilutions against the mycobacteria and with a range of dilutions against Citrobacter freundii. The degree of agglutination was scored as $\mathbf{0}$ for no agglutination, 1 for weak but definite agglutination, 2 for gross agglutination, and 3 for heavy agglutination of the coccoid rods and Mycobacteria. In tests with Citrobacter freundii the endpoint was taken as the highest dilution which gave a score of 1 .

In a subsequent double-blind study of eubacteria and peptostreptococci conducted in Rotterdam, a slightly different technique was used. Sera and bacteria $\left(5 \times 10^{8} / \mathrm{ml}\right)$ were mixed, placed on slides, and shaken. The results were read macroscopically after shaking for five minutes.

All tests were conducted without knowledge of the source of serum samples.

COMPLEMENT FIXATION TEST FOR

ANTIBODIES AGAINST CHLAMYDIA

The antigen for Chlamydia psittaci had been grown on embryonated hens' eggs, and cross-reacted with Chlamydia trachomatis. Guinea-pig serum was used as the source of complement and the serum dilutions were tested against an egg yolk antigen as a control. A positive test was recorded when sera reacted at a higher dilution against the Chlamydia antigen than against the egg yolk antigen. For each sample of serum the titre was recorded as the ratio of the dilution which reacted with Chlamydial antigen to the dilution reacting with egg yolk antigen.

\section{Results}

None of the sera which were tested showed agglutination with Clostridium colinum and the incidence of antibodies to Campylobacter sputorum was very low (Table 1). In contrast, agglutinating antibodies to Citrobacter freundii were present in almost all of the patients with inflammatory bowel disease and controls (Table 2); the mean titre was higher in sera from patients with Crohn's disease than controls but this was not statistically significant.

Mycobacterium paratuberculosis strains M26 and M27 failed to be agglutinated by any of the sera 
Table 1 Antibodies to Campylobacter sputorum and Clostridium colinum

\begin{tabular}{lll}
\hline & Camp. sputorum & Cl. colinum \\
\hline Crohn's disease & $1 / 62$ & $0 \cdot 61$ \\
Ulcerative colitis & $1 / 35$ & $0 / 34$ \\
Controls & $1 / 58$ & $0 / 55$
\end{tabular}

Number of patients with agglutinins against Campylobacter sputorum and Clostridium colinum; the denominator is the number of sera tested in each group.

Table 2 Antibodies to Citrobacter freundii

\begin{tabular}{llll}
\hline & $\begin{array}{l}\text { Positive in } \\
\text { neat serum }\end{array}$ & Number & $\begin{array}{l}\text { Mean titre } \\
\left(\log _{10}\right)\end{array}$ \\
\hline Crohn's disease & $62 / 62$ & 31 & $1 \cdot 65 \pm 0.25$ \\
Ulcerative colitis & $28 / 35$ & - & - \\
Controls & $58 / 58$ & 35 & $1 \cdot 56 \pm 0.27$
\end{tabular}

Number of patients with agglutinins against Citrobacter freundii. In 31 patients and 35 controls the titre at which a positive result occurred was determined; the mean and standard deviation for those titres is given.

tested. However, M. paratuberculosis (M28) and M. avium (M41) were agglutinated by most sera (Table 3). Sera from patients with Crohn's disease were not more reactive than the controls.

Complement fixing antibodies against Chlamydia were not significantly more common in Crohn's disease and ulcerative colitis sera than in control sera (Table 4) and the titres were not higher.

Agglutinins against stains of the commensal anaerobes Eubacterium and Peptostreptococcus were found more often in Crohn's disease sera than in ulcerative colitis or controls sera (Table 5). Of the four strains examined, strain ME46 appeared most 'specific' for Crohn's disease. If one considers sera which agglutinated either ME46 or two of the other strains then the difference between patients with Crohn's disease and the other groups is highly significant $\left(\chi_{2}^{2}=23 ; \quad \mathrm{P}<0.001\right) . \quad \chi^{2}$ analysis on 1 degree of freedom with a continuity correction showed that the difference between patients with Crohn's disease and ulcerative colitis was significant
Table 3 Agglutinins against Mycobacterium paratuberculosis, Strain M28 and Mycobacterium avium, Strain $M 4 I$

\begin{tabular}{|c|c|c|c|c|}
\hline & \multicolumn{2}{|l|}{ M28 } & \multicolumn{2}{|l|}{$M 41$} \\
\hline & $\begin{array}{l}\text { Number } \\
\text { positive at } \\
\text { dilution } 1 / 1\end{array}$ & $\begin{array}{l}\text { Mean } \\
\text { score }\end{array}$ & $\begin{array}{l}\text { Number } \\
\text { positive at } \\
\text { dilution } 1 / 1\end{array}$ & $\begin{array}{l}\text { Mean } \\
\text { score }\end{array}$ \\
\hline $\begin{array}{l}\text { Crohn's disease } \\
\text { Ulcerative }\end{array}$ & $19 / 24$ & $1.08 \div 0.83$ & $23 / 24$ & $1 \cdot 79 \pm 0 \cdot 83$ \\
\hline $\begin{array}{c}\text { colitis } \\
\text { Controls }\end{array}$ & $\begin{array}{l}17 / 24 \\
19 / 24\end{array}$ & $\begin{array}{l}0.92=0.72 \\
1.29=0.86\end{array}$ & $\begin{array}{l}20 / 24 \\
22 / 24\end{array}$ & $\begin{array}{l}1.79 \pm 1.06 \\
1.67 \pm 0.76\end{array}$ \\
\hline
\end{tabular}

Twenty-four samples of sera were tested from each group against both mycobacteria, and the denominator gives the number which were positive using a 1 in 4 dilution of the serum. The degree of agglutination was scored 1 for weak, 2 gross, and 3 for very heavy agglutination: the mean $-\mathrm{SD}$ of these scores are given.

Table 4 Complement fixing antibodies against Chlamydia

\begin{tabular}{lll}
\hline & $\begin{array}{l}\text { Number } \\
\text { positive }\end{array}$ & $\begin{array}{l}\text { Mean positive } \\
\text { titres }\end{array}$ \\
\hline Crohn's disease & $30 / 62(48.4 \%)$ & $4 \cdot 60-4.07$ \\
Ulcerative co!itis & $19 / 35(54.3 \%)$ & $3 \cdot 05+1 \cdot 54$ \\
Controls & $18 / 57(31.6 \%)$ & $4 \cdot 32-1.80$
\end{tabular}

The number of positive complement fixation tests for sera against Chalamydia; a positive was recorded when sera reacted at a higher dilution against Chalamydia antigen compared with egg yolk antigen.

$\left(\%^{2}{ }_{1}=6.54 ; \mathrm{P}<0.02\right)$ and that the difference between patients with Crohn's disease and controls was significant $(\mathrm{P}<0.001)$.

\section{Discussion}

The most striking finding from our results was that circulating antibodies to certain strains of Peptostreptococcus and Eubacterium were present in significantly more patients with Crohn's disease $(54 \%)$ than in patients with ulcerative colitis $(11 \%)$ or normal controls. These findings confirm Wensinck's, ${ }^{1213}$ earlier observations and those from a small joint study which gave similar results in Rotterdam and Cardiff. Wensinck's work followed

Table 5 Agglutinins against Peptostreptococcus productus, Strain $c_{18}$ and Eubacterium contortum, Strains $M E_{44}$ and $M E_{47}$, and Eubacterium rectale, Strain $M E_{46}$

\begin{tabular}{|c|c|c|c|c|c|}
\hline & \multicolumn{4}{|c|}{ Proportion positive against } & \multirow{2}{*}{$\begin{array}{l}\text { Proportion positive against } M E_{44} \\
\text { or any two of } C_{18}, M E_{44} \text {, or } M E_{47}\end{array}$} \\
\hline & $C_{18}$ & $M E_{44}$ & $M E_{46}$ & $M E_{47}$ & \\
\hline $\begin{array}{l}\text { Crohn's disease } \\
\text { Ulcerative colitis } \\
\text { Controls }\end{array}$ & $\begin{array}{l}6 / 24 \\
1 / 18 \\
1 / 26\end{array}$ & $\begin{array}{l}7 / 24 \\
0 / 18 \\
1 / 26\end{array}$ & $\begin{array}{r}12 / 24 \\
2 / 18 \\
0 / 26\end{array}$ & $\begin{array}{l}6 / 24 \\
5 / 18 \\
4 / 26\end{array}$ & $\begin{array}{c}13 / 24(54 \%) \\
2 / 18(11 \%) \\
0 / 26(0 \%)\end{array}$ \\
\hline
\end{tabular}

The number of sera which were positive are represented by the numerator and the total sera tested by the denominator. The number of sera with a positive result to $M E_{46}$ or any two of the other organisms is in the right hand column. 
his initial finding that the number of these organisms was substantially increased in the stools of patients with Crohn's disease. We are reluctant to attribute any causative role to the organisms but the findings could be of some value in screening the relatives of patients. It is unfortunate that only half of the patients gave positive results and about $10 \%$ of those with colitis were also positive.

There has recently been considerable interest in the possible role of Mycobacteria in Crohn's disease. Evidence implicating Mycobacteria kansasii involves its isolation from a mesenteric lymph node, serological studies, and delayed type skin tests. ${ }^{16}{ }^{17}$ However, by immunofluorescence $M$. kansasii antigens were not detected in the affected bowel mucosa of patients with Crohn's disease. ${ }^{18}$ As far as we are aware, Mycobacterium paratuberculosis has not been investigated in human Crohn's disease. In our study three strains of $M$. paratuberculosis and one $M$. avium strain were tested. With two of the $M$. paratuberculosis strains none of the sera tested produced agglutination; with the third $M$. para tuberculosis strain and the $M$. avium strain agglutination was produced by sera from most of the patients and controls with no significant difference between the groups.

Several groups have investigated the possible role of Chlamydia with variable results. ${ }^{911} 19$ We have been unable to demonstrate any significant difference between our patients and those with colitis and the results give no support to the suggestion that Chlamydia plays a role in the aetiology of Crohn's disease.

Similar investigations have been undertaken by Tabaqchali et al. ${ }^{20}$ who examined 159 subtypes of Escherichia coli. Agglutinins were found in most of 30 patients with inflammatory bowel disease and the mean number of positives in individual subjects was 13.8 in Crohn's disease, 7.8 in ulcerative colitis, and 1.5 in controls. The higher antibody titre in patients compared with controls is attributed to an increase in the antigenic load entering the circulation through diseased bowel wall and overloading the liver 'filter' system. The possibility of a pathogenic relationship between the bacterial antigens and chronic inflammatory bowel disease was unlikely in view of the large number of Escherichia coli serotypes involved. It was more likely that the phenomenon was secondary to the disease process, although these and other bacteria such as Peptostreptococci and Eubacteria may play a role in perpetuating it. In a study of bacterial flora associated with the intestinal mucosa of 14 patients with Crohn's disease and 16 controls there was no statistical difference in the number of bacteria associated with Crohn's tissue compared with normal tissue, although entero- bacteria were more commonly associated with the Crohn's tissue. ${ }^{21}$ This contrasts with earlier work by Wensinck. ${ }^{12} 13$

In view of the disappointing efforts to identify a causative organism, we felt it was worth examining some bacteria which were known to cause inflammatory bowel disease in animals. We were encouraged to pursue this course because some of the organisms in animals have proved very difficult to culture by conventional techniques and in some instances grow intracellularly. During the last few years bacteria related to two of the organisms have been found to be responsible in man for acute diarrhoea (Campylobacter jejuni and coli) ${ }^{22} 23$ and the colitis following antibiotic administration (Clostridium difficile). ${ }^{24}{ }^{25}$ Our search for antibodies to Campylobacter sputorum subsp. mucosalis (the cause of porcine intestinal adenomatosis or 'Crohn's disease' in pigs), ${ }^{26}{ }^{27}$ Clostridium colinum (the cause of quail enteritis in fowl), ${ }^{456}$ and a variant of Citrobacter freundii (the cause of transmissible murine colonic hyperplasia) ${ }^{8}$ gave no encouragement to the suggestion that these organisms have a causative role in Crohn's disease, although a negative agglutination test does not exclude the possibility that they may play a part.

We should like to like to thank Mr P R J Matthews, of the Institute of Research in Animal Diseases, Compton, Newbury, England; for providing mycobacterial antigens, and Dr Moore, of the Virginia Polytechnic Institute and State University, Blacksburg, Virginia, USA, for providing Peptostreptococcus productus.

\section{References}

${ }^{1}$ Mayberry JF, Rhodes J, Hughes LE. Incidence of Crohn's disease in Cardiff between 1934 and 1977. Gut 1979; 20: 602-8.

${ }^{2}$ Mayberry JF, Rhodes J, Heatley RV. Infections which cause ileo-colic disease in animals; are they relevant to Crohn's disease? Gastroenterology 1980; 70: 1080-84.

${ }^{3} \mathrm{M}$ 'Fadyean J. The histology of the lesions of Johne's disease. J Comp Pathol 1918; 31: 73-87.

${ }^{4}$ Berkhoff GA, Campbell SG. Etiology and pathogenesis of ulcerative enteritis ('Quail disease'). The experimental disease. Avian Dis 1974; 18: 205-12

${ }^{5}$ Berkhoff GA, Campbell SG, Naylor HB. Etiology and pathogenesis of ulcerative enteritis ('Quail disease'). Isolation of causative anaerobe. Avian Dis 1974; 18: 186-94.

${ }^{6}$ Berkhoff GA, Campbell SG, Naylor HB. Etiology and pathogenesis of ulcerative enteritis ('Quail disease'). Characterisation of the causative anaerobe. Avian Dis 1974; 18: 195-204.

${ }^{7}$ Lawson GHK, Rowland AC. Intestinal adenomatosis in the pig: a bacteriological study. Res Vet Sci 1974; 17: $331-36$. 
${ }^{8}$ Barthold, SW, Coleman GL, Bhatt PN, Osbaldiston GW, Jonas AM. The etiology of transmissible murine colonic hyperplasia. Lab Anim Sci 1976; 26: 889-94.

${ }^{9}$ Schuller JL, Piket-Van Ulsen J, Veeken IVD, Michel MF, Stolz E. Antibodies against chlamydia of lymphogranulomavenerum type in Crohn's disease. Lancet 1979; 1: 19-20.

${ }^{10}$ Swarbrick ET, Kingham JGC, Price HL, Blackshaw AJ, Griffiths PD, Darougar S, Buckell NA. Chlamydia, cytomegalovirus and Yersinia in inflammatory bowel disease. Lancet 1979; 2: 11-12.

"Taylor-Robinson D, O'Morain CA, Thomas BJ, Levi AJ. Low frequency of chlamydial antibodies in patients with Crohn's disease and ulcerative colitis. Lancet 1979; 1 : 1162-63.

${ }^{12}$ Wensinck F. The faecal flora of patients with Crohn's disease. Antonie Van Leeuwenhoek 1975; 41: 214-15.

${ }^{13}$ Wensinck F. Faecal flora of Crohn's patients. Serological differentiation between Crohn's disease and ulcerative colitis. In: Weterman IT, Pena AS, Booth $\mathrm{CC}$, eds The management of Crohn's disease. Amsterdam: Excerpta Medica, 1976: 103-7.

${ }^{14}$ Lawson GHK, Rowland AC, Roberts L. The surface antigens of Campylobacter sputorum subspecies mucosalis. Res Vet Sci 1977; 23: 378-82.

${ }^{15}$ Matthews PRJ, Brown A, Collins P. The use of polyvalent sera for the serotyping of mycobacterium within the Mycobacterium avium-M. intracellulareM. scrofulaceum complex. J Appl Bact 1979; 46: 425-30.

${ }^{16}$ Burnham WR, Lennard-Jones JE, Stanford JL, Bird AG. Mycobacteria as a possible cause of inflammatory bowel disease. Lancet 1978; 2: 693-96.

${ }^{17}$ White SA, Nassau E, Burnham WR, Stanford JE, Lennard-Jones JE. Further evidence for a myco- bacterial aetiology of Crohn's disease. (Abstract.) Gut 1978; 19: 443-44.

${ }^{18}$ Whorwell PJ, Davidson IW, Beeken WL, Wright R. Search by immunofluorescence for antigens of rotavirus, Pseudomonas maltophilia and Mycobacterium kansasii in Crohn's disease. Lancet 1978; 2: 697.

${ }^{19}$ Tomenius J, Larre E, Lindgren I, Blumenthal B, Lindewall G. Positive Frei tests in 7 cases of morbus Crohn (regional ileitis). Gastroenterologia 1963; 99: 368-73.

${ }^{20}$ Tabaqchali S, O'Donoghue DP, Bettelheim KA. Escherichia coli antibodies in patients with inflammatory bowel disease. Gut 1978; 19: 108-13.

${ }^{21}$ Peach S, Lock MR, Katz D, Todd IP, Tabaqchali S. Mucosal-associated bacterial flora of the intestine in patients with Crohn's disease and in a control group. Gut 1978; 19: 1034-42.

${ }^{22}$ Butzler JP, Dekeyser P, Detrain M, Dehaen F. Related vibrio in stools. J Pediatr $1973 ; \mathbf{8 2}$ : 493-95.

${ }^{23}$ Skirrow MB. Campylobacter enteritis-a 'new' disease. Br Med J 1977; 2: 9-11.

${ }^{21}$ Bartlett JG, Moon N, Chang TW, Taylor N, Onderdonk AB. The role of Clostridium difficile in antiobioticassociated pseudomembranous colitis. Gastroenterology 1978; 75: 778-82.

${ }^{25}$ George RH, Symonds JM, Dimock F, et al. Identification of Clostridium difficile as a cause of pesudomembranous colitis. Br Med J 1978; 1 : 695.

${ }^{26}$ Crohn BB, Turner DA. Porcine ileitis. Gastroenterology 1952; 20: 350-1.

${ }^{27}$ Lawson GHK, Rowland AC, Wooding P. The characterisation of Campylobacter sputorum subspecies mucosalis isolated from pigs. Res Vet Sci 1975; 18: 121-6. 